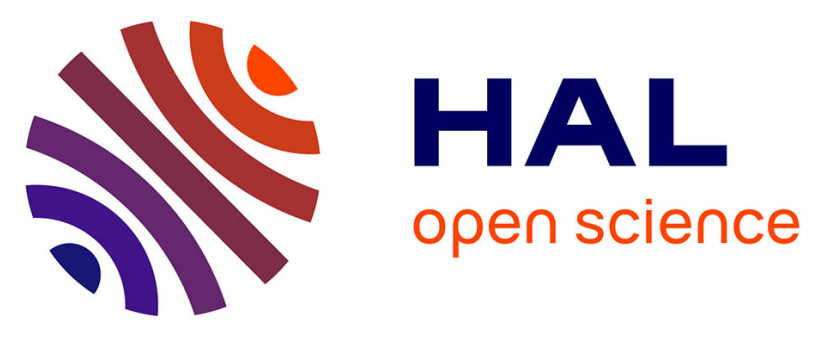

\title{
Toward the understanding of temperature effect on bonding strength, dimensions and geometry of 3D-printed parts
}

Hamidreza Vanaei, Kaddour Raissi, Michael Deligant, Mohammadali Shirinbayan, Joseph Fitoussi, Sofiane Khelladi, Abbas Tcharkhtchi

\section{To cite this version:}

Hamidreza Vanaei, Kaddour Raissi, Michael Deligant, Mohammadali Shirinbayan, Joseph Fitoussi, et al.. Toward the understanding of temperature effect on bonding strength, dimensions and geometry of 3D-printed parts. Journal of Materials Science, 2020, 55 (29), pp.14677-14689. 10.1007/s10853020-05057-9 . hal-02974929

\section{HAL Id: hal-02974929 \\ https://hal.science/hal-02974929}

Submitted on 22 Oct 2020

HAL is a multi-disciplinary open access archive for the deposit and dissemination of scientific research documents, whether they are published or not. The documents may come from teaching and research institutions in France or abroad, or from public or private research centers.
L'archive ouverte pluridisciplinaire HAL, est destinée au dépôt et à la diffusion de documents scientifiques de niveau recherche, publiés ou non, émanant des établissements d'enseignement et de recherche français ou étrangers, des laboratoires publics ou privés. 


\title{
Toward the understanding of temperature effect on bonding strength, dimensions and geometry of 3D- printed parts
}

\author{
H. R. Vanaei ${ }^{1,2, \star}$ (I) K. Raissi ${ }^{1}$, M. Deligant ${ }^{1}$, M. Shirinbayan ${ }^{2}$, J. Fitoussi ${ }^{2}$, S. Khelladi ${ }^{1}$, and \\ A. Tcharkhtchi ${ }^{2}$ \\ ${ }^{1}$ Arts et Metiers Institute of Technology, CNAM, LIFSE, HESAM University, 75013 Paris, France \\ ${ }^{2}$ Arts et Metiers Institute of Technology, CNRS, CNAM, PIMM, HESAM University, 75013 Paris, France
}

\begin{abstract}
Fused filament fabrication (FFF), which is an additive manufacturing technique, opens alternative possibilities for complex geometries fabrication. However, its use in functional products is limited due to anisotropic strength issues. Indeed, the strength of FFF fabricated parts across successive layers in the build direction ( $Z$ direction) can be significantly lower than the strength in $X-Y$ directions. This strength weakness has been attributed to poor bonding between printed layers. This bonding depends on the temperature of the current layer being deposited-at melting temperature $\left(T_{\mathrm{m}}\right)$-and the temperature of the previously deposited layer. It is assumed that depositing a layer at $T_{\mathrm{m}}$ on a layer at temperature around crystallization temperature $\left(T_{c}\right)$ would enable higher material crystallinity and thus better bonding between previous and present layers. On the contrary, if the previous layer temperature is below $T_{c}$, material crystallinity will be low and bonding strength weak. This paper aims at studying the significant effect of temperature difference $(\Delta T)$ between previous and current deposited layers temperatures on (1) inter-layers bonding strength improvement and (2) part dimensions, geometry and structure stability. A 23\% increase in the inter-layers bonding strength for previous layer temperature slightly higher than $T_{\mathrm{c}}$ reported here confirms the above assumption and offers a first solution toward the increase in inter-layers bonding strength in FFF.
\end{abstract}




\section{GRAPHICAL ABSTRACT}
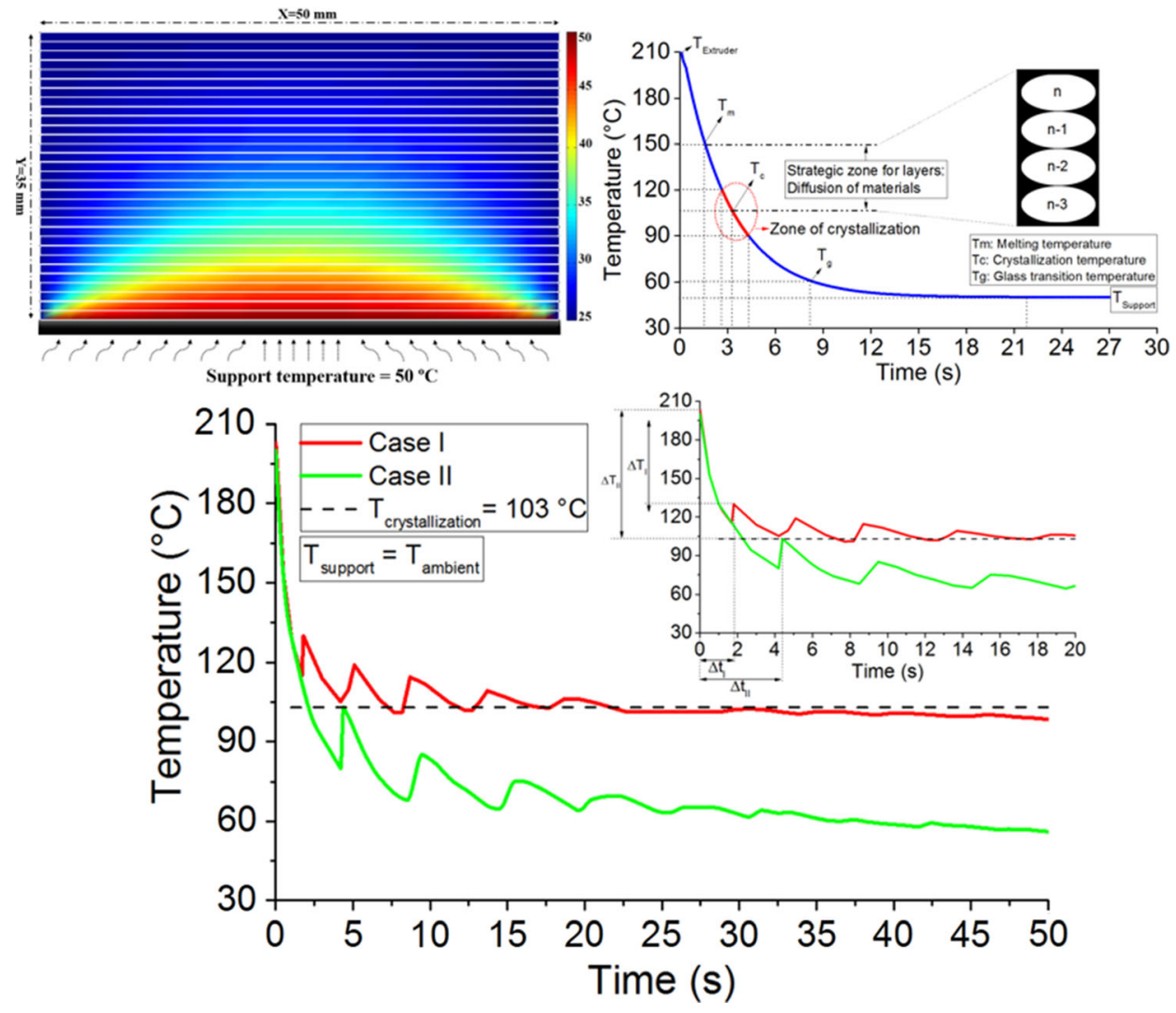

\section{Introduction}

Additive manufacturing (AM) process comprises various techniques allowing the construction of three-dimensional parts of complex geometry, difficult or impossible to manufacture using traditional manufacturing processes [1, 2]. Fused filament fabrication (FFF), also known as $3 \mathrm{D}$ printing, is one of those AM processes used to produce prototypes in different industrial sectors such as aerospace, medical and automotive [3, 4]. In FFF, the most important materials for parts manufacturing are thermoplastic polymers [5]. Accordingly, several parameters affect the manufactured part quality [6, 7], like the temperature profile of the polymer and consequently the inter-layers bonding [8-10]. It is therefore important to understand how the process parameters affect the evolution of filaments temperature as mentioned [11-14].

The problems of effective bonding, reduced strength and mechanical performance are a major concern of manufactured 3D-printed structures. In the process of parts fabrication, as the deposition progresses, the hot filament is deposited onto filaments that were previously deposited and which are in the process of cooling. The contact between the hot filament and the previous deposited filaments causes re-heating of the latter. At the interface of adjacent filaments, temperature rises above the crystallization temperature $\left(T_{\mathrm{c}}\right)$ and proper bonding take place.

Therefore, in order to foster material crystallization at the interface between filaments and allow better 
molecular chain re-arrangement during the deposition of the melted filament, the previously deposited filaments should be sufficiently hot, probably around crystallization temperature. Higher temperature of previously deposited filament could cause molten material flows and deformation of subsequent deposited layers. In case of lower previously deposited filament temperature, the molecular chain of the deposited material does not have enough time to be re-arranged, causing lower bonding of the two adjacent filaments [15].

Nowadays, one of the challenging features in order to improve the bonding of 3D-printed parts is to optimize the temperature at the interface between previous and current deposited filaments. In fact, control of previous filament cooling speed is a crucial factor for interface bonding for the following reasons:

- High cooling rate causes poor interface bonding.

- Low cooling rate causes deformation of fabricated parts due to the effect of gravity, etc.

Therefore, controlling the cooling speed or temperature profile of deposited filaments acts as an important criterion in the strengthening of 3D-printed parts [8]. Numerous numerical- and experimental-based researches investigated this criterion for different polymers in order to characterize thermal behavior of the filaments. Costa et al. [16] developed a model based on the heat transfer between filaments during deposition and predicted temperature and adhesion quality of the 3D-printed parts. This model showed a good agreement with experimental data. Sun et al. [15] studied the mechanisms controlling the bond formation for ABS filaments in FFF process. They showed that temperature and variation in the convective conditions have a strong effect on thermal distribution and overall quality of the bond strength. In another study, they focused on the thermal behavior for PLA polymer filaments [17]. They tried to understand both numerically and experimentally the effect of nozzle and platform temperatures, extrusion speed and layer thickness on bond formation. However, recent researches demonstrated that cyclic cooling and re-heating of filaments during FFF have an impact on the sintering by considering the effect of temperature on viscosity [18, 19]. Beside this, inter-layer adhesion has been widely investigated. Yin et al. [20] investigated both numerically and experimentally the effect of process parameters on the bonding strength of multi-material, and they found that the variation of temperature profile has an impact on mechanical behavior of the printed parts. Consequently, they later focused on the improvement of inter-layer bonding by addition of bimodal blends to the polymeric parts and found that low molecular weight (LMW) additives reinforce interfaces and reduce anisotropy [21, 22]. These efforts led to the application of novel materials, using acrylonitrilebutadiene-styrene (ABS) as a matrix thermoplastic polyurethane (TPU) as an additive, allowing 3Dprinting without platform heating [23].

One of the most important key factors that researchers are working on is "pre-heating of the previously deposited filaments". Partain [24] used a nozzle to blow hot air onto the fabricated part to decrease the cooling rate of deposited filaments, while Kishore et al. [25] exerted infrared ray to evaluate the strength of fabricated parts. Despite the interesting results they obtained, surface exposure was observed because of the radiation of infrared ray. However, a local pre-heating laser was also applied to the layered zone near the extruder to increase the interface temperature. The pre-heated sample had more strength, elasticity and toughness, but surface re-flow causes damage and affects the quality of printed parts [26].

To sum up, in the case of FFF process, the thermal aspect seems to play a key role as for inter-filaments bonding and dimensions of 3D-printed parts. The temperature of previously deposited filament $\left(T_{\text {pre- }}\right.$ vious) strongly affects the material crystallinity occurring at the interface during the deposition of the current filament at $T_{\mathrm{m}}$. In order to investigate the influence of $T_{\text {previous }}$ on bonding and other dimensional aspects, an experimental study is conducted. For the purpose of this study, $T_{\text {previous }}$ ranges between the room temperature $\left(T_{\mathrm{r}}\right)$ and the crystallization temperature $\left(T_{\mathrm{c}}\right)$.

\section{Experimental study}

\section{Preliminary observations}

During FFF part printing, the polymer filament undergoes several successive cooling and re-heating due to the presence of two neighboring thermal sources: (1) the extruder and (2) the heating bed (support). On leaving the extruder, the filament cools down from a temperature of $210^{\circ} \mathrm{C}$ to the room 


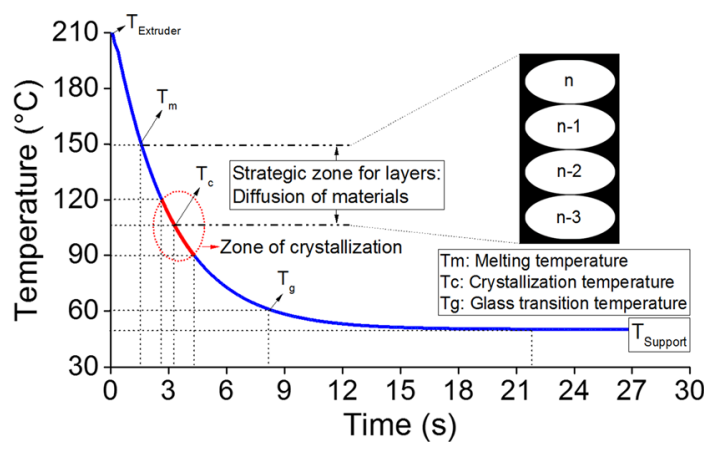

Figure 1 Cooling of a single deposited filament.
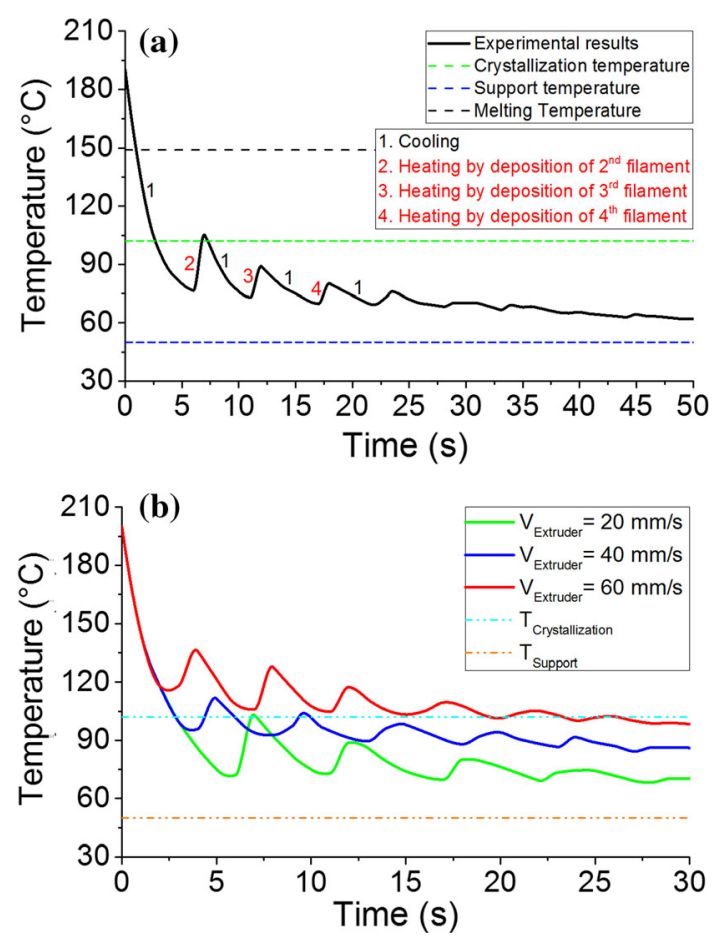

Figure 2 Results of the in situ measurement for the temperature evolution of a a sample with process parameters: $\mathrm{T}_{\text {ext }}=210{ }^{\circ} \mathrm{C}$, $T_{\text {supp. }}=50{ }^{\circ} \mathrm{C}, V_{\text {ext }}=20 \mathrm{~mm} \mathrm{~s}^{-1}, h=0.2 \mathrm{~mm}$ and $\mathbf{b}$ samples in various print speed.

temperature, passing through the melting temperature and later the crystallization temperature (Fig. 1).

Once deposited, this filament will transfer part of its heat to the neighboring filaments previously deposited. The latter will undergo every new filament deposition, successive heating/cooling cycles which could affect the mechanical and dimensional results. Figure 2a shows the cooling profile of first deposited filament at $X=5 \mathrm{~mm}$ from the start of deposition at the following conditions: extruder temperature $\left(T_{\mathrm{Ext}}=210{ }^{\circ} \mathrm{C}\right)$, support temperature $\left(T_{\text {Supp }}=50{ }^{\circ} \mathrm{C}\right)$, print speed of $20 \mathrm{~mm} \mathrm{~s}^{-1}$ and layer height of $0.2 \mathrm{~mm}$. A cyclic evolution of the temperature of the first deposited filament, due to the deposition of the following filaments, could be noted. Each peak refers to a new filament deposition and proves that two adjacent filaments contact occurred. Figure $2 \mathrm{~b}$ shows the cooling profile of first deposited filament for different printing speeds. We note that increasing the printing speed avoids filaments cooling down before new filament deposition.

Finally, in addition to the heat transfer from the extruder, these filaments also undergo heat transfer originated by the heating bed. This heat transfer from the heating bed to the filaments will increase the anisotropy of the sample. Heat diffusion equation was applied by replacing the objective to a set of nodes at steady state. Then, derivative of temperature with respect to $X$ and $Y$ directions was calculated using the following equation and taking into account the grid generation:

$$
\begin{aligned}
& \frac{\partial^{2} T}{\partial x^{2}}+\frac{\partial^{2} T}{\partial y^{2}}=0 \\
& \left.\left.\left[\frac{T_{i-1, j}^{k}-2 T_{i, j}^{k}+T_{i+1, j}^{k}}{\Delta x^{2}}\right)+\frac{T_{i, j-1}^{k}-2 T_{i, j}^{k}+T_{i+1, j}^{k}}{\Delta y^{2}}\right)\right] \\
& =0
\end{aligned}
$$

The temperature of node $(i, j)$ was obtained as follows:

$T_{i, j}=\frac{1}{4}\left(T_{i, j-1}+T_{i-1, j}+T_{i+1, j}+T_{i, j+1}\right)$

Concerning the dimensions of the object (Fig. 3a, b), these are applied to a source of heat and injected in MATLAB ${ }^{\circledR}$ based on the following boundary conditions:

- $\Delta x=\Delta y$ (Consideration of Gauss-Seidel iterative)

- $d t=0$ (Consideration of steady state)

Based on the obtained results in Fig. 3c, it is observable that the source of heat contributes to the anisotropy of the fabricated parts and demonstrates the effect of the heating bed on the temperature distribution in the printed part.

\section{Test design and samples printing}

Heat transfers from the extruder and the heating bed have a significant influence on the printed part. Our study considers only heat generated by the extruder 

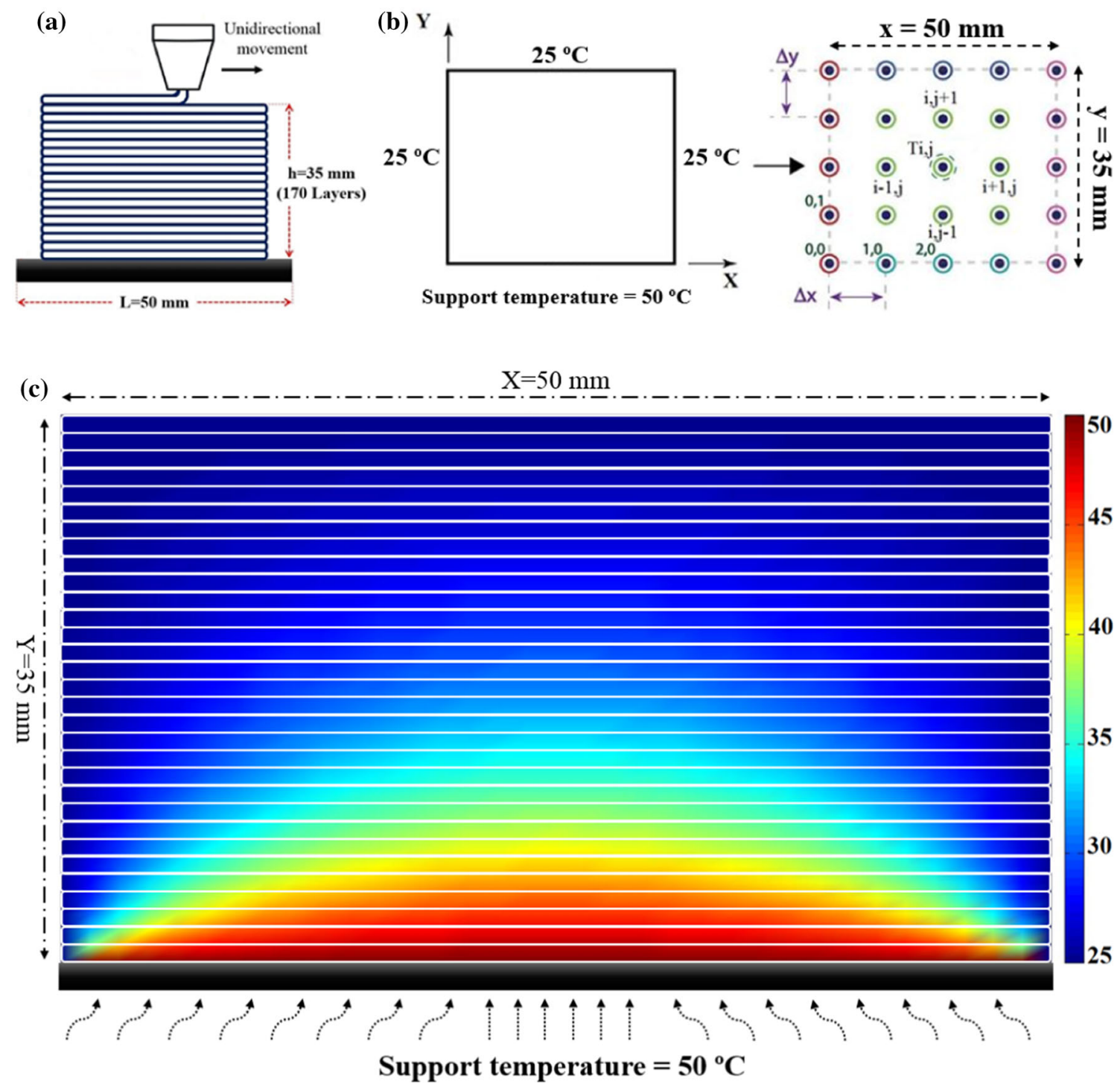

Figure 3 Representation of $\mathbf{a}$ schematic of the test case, $\mathbf{b}$ nodes for finite difference method, $\mathbf{c}$ obtained results at steady state.

Figure 4 Typical image representing the inter-filaments bonding.

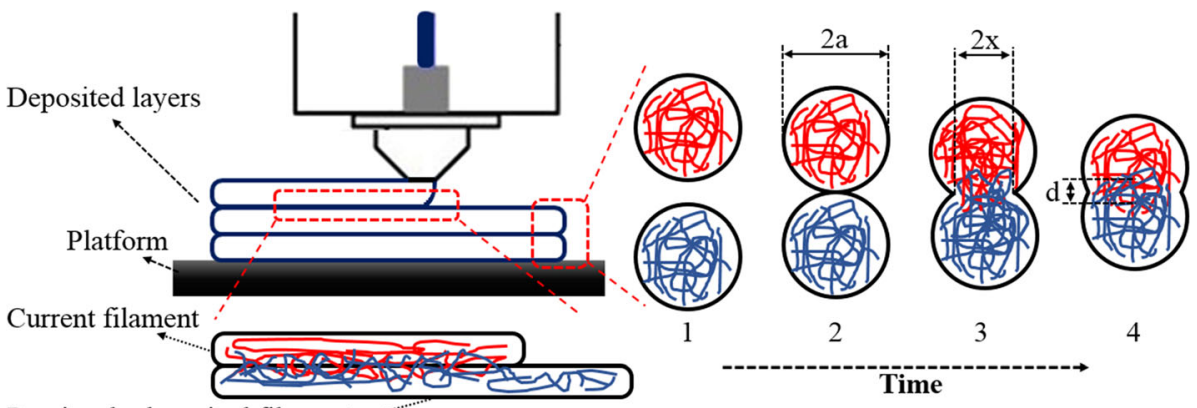

Previously deposited filament

and transferred to the printed part through the filaments. The heating bed effect, as presented in Fig. 3, is cancelled by setting its temperature to $0{ }^{\circ} \mathrm{C}$ (turn off the heating bed and let it at ambient temperature).
In this context, we paid particular attention to the temperature difference, $\Delta T$, between the temperature of the current filament ( $T_{\text {extruder }}$ ) and the temperature of the previously deposited filament, $T_{\text {previous }}$ (Fig. 4). 
This experimental study aims at investigating and understanding precisely how $\Delta T$ affects material crystallinity at the interface between previous and current deposited filaments, and consequently the inter-filaments bonding and dimensional results.

The temperature difference $(\Delta T)$ can be expressed as follows:

$\Delta T=T_{\text {Extruder }}-T_{\text {Previous }}=210^{\circ} \mathrm{C}-T_{\text {Previous }}$

where $T_{\text {extruder }}$ is the temperature of current filament and $T_{\text {previous }}$ is the temperature of the previously deposited filament.

The $\Delta T$ depends on the extruder speed, $V_{\text {extruder, }}$ and the distance travelled by the extruder before redepositing the melting filament in the same point. According to the filament's cooling curve presented in Fig. 1, the longer the distance travelled by the extruder, the higher the cooling time $(\Delta t)$ and consequently $\Delta T$. For example, based on Fig. 1 , if $T_{\text {previ- }}$ ous is set equal to $T_{\mathrm{c}}\left(\sim 103{ }^{\circ} \mathrm{C}\right)$, then $\Delta T$ is around $107^{\circ} \mathrm{C}$ and the corresponding cooling time is $\Delta t=$ $3.3 \mathrm{~s}$. These values mean that if the cooling time between two successive filaments in a given point (P) equals $3.3 \mathrm{~s}$, then the current filament at temperature $T_{\text {extruder }}\left(210{ }^{\circ} \mathrm{C}\right)$ will be deposited onto a previously deposited filament at temperature $T_{\mathrm{c}}$ $\left(103{ }^{\circ} \mathrm{C}\right)$.

For the purpose of this experimental study, the temperature of the previously deposited filament ranges around the crystallization temperature. Indeed, the zone around crystallization temperature is considered as a strategic zone. The extruder speed is kept constant in order to avoid any influence driven by this speed on the printing result. Three solid blocks per each case are printed following the designed path with constant extruder speeds ( $V_{\text {ex- }}$ truder and $\left.V_{\text {return }}\right)$ as presented in Fig. 5.
Finally, according to the ISO 37-3 standard (Fig. 6c, d), the quasi-static tensile specimens were cut from the printed solid blocks using a proper standard mold and a press machine as shown in Fig. 6a, b: three samples for case I and nine samples for case II (three for each location).

According to Fig. 5, the cooling time of the filament can be expressed as follows:

$\Delta t=L / V_{\text {extruder }}+L / V_{\text {reverse }}$

where $L$ is the length of test piece, $V_{\text {extruder }}$ is the speed of the extruder (material deposition), and $V_{\text {re- }}$ verse is the reverse speed of the extruder (no material deposition).

Based on the printer capabilities, reverse speed was set to a maximum speed of $40 \mathrm{~mm} \mathrm{~s}^{-1}$ and extruder speed (deposition) was set to $12 \mathrm{~mm} \mathrm{~s}^{-1}$.

The length of the test piece was chosen in such a way as to reduce the cooling time, $\Delta t$, for case study I and to increase $\Delta t$ for case study II (Fig. 6). In that respect, these lengths were set equal to $15 \mathrm{~mm}$ for case I and $40 \mathrm{~mm}$ for case II. Thanks to Eq. 5, $\Delta t$ is calculated for each case:

- Case I: cooling time is $\Delta t_{\mathrm{I}}=1.625 \mathrm{~s}$

- Case II: cooling time is $\Delta t_{\text {II }}=4.333 \mathrm{~s}$

Based on Fig. 1:

- $\Delta t_{\mathrm{I}}=1.625 \mathrm{~s}$ corresponds to $T_{\text {previous }}=140^{\circ} \mathrm{C}$ and $\Delta T_{\mathrm{I}}=210{ }^{\circ} \mathrm{C}-140{ }^{\circ} \mathrm{C}=70{ }^{\circ} \mathrm{C}$

- $\Delta t_{\mathrm{II}}=4.333 \mathrm{~s}$ corresponds to $T_{\text {previous }}=90^{\circ} \mathrm{C}$ and $\Delta T_{\mathrm{II}}=210{ }^{\circ} \mathrm{C}-90^{\circ} \mathrm{C}=120^{\circ} \mathrm{C}$

Table 1 summarizes the two case studies conditions as follows:

A commercially available orange PLA filament with diameter $1.75 \mathrm{~mm}( \pm 0.01 \mathrm{~mm})$ and density $\rho=1.24 \mathrm{gr} \mathrm{cm}^{-3}$ was used for test parts printing.

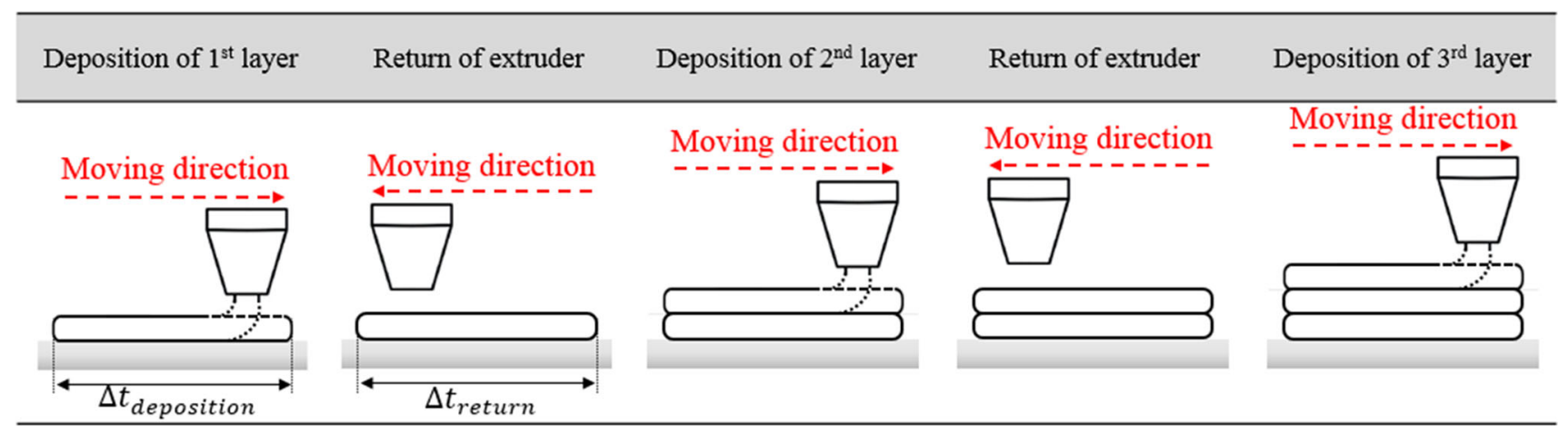

Figure 5 Typical image showing the deposition mechanism. 

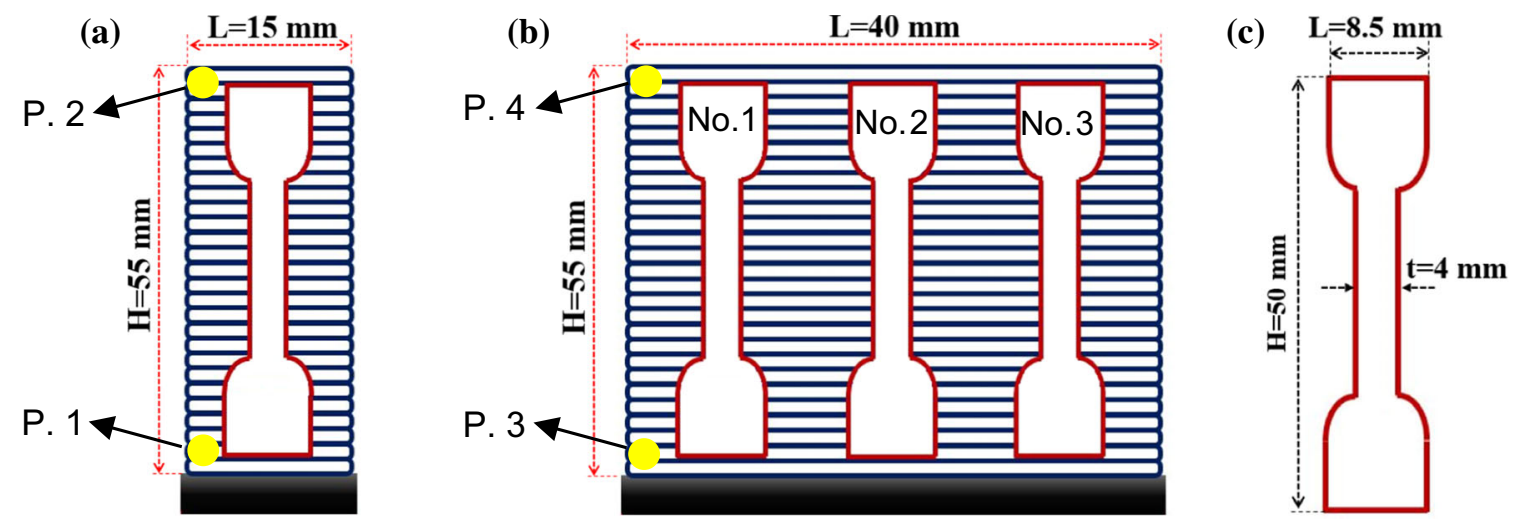

(d)

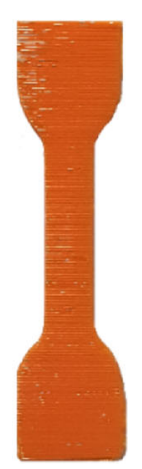

Figure 6 Typical image of a case I with representation of selected locations (points 1 and 2) for DSC characterization, $\mathbf{b}$ case II with representation of selected locations (points 3 and 4) for DSC characterization and classification of tensile sample in consideration of the distance from start of deposition, $\mathbf{c}$ designed samples based on ISO 37-3 standard, $\mathbf{d}$ fabricated samples.

Table 1 Calculated values for both cases

\begin{tabular}{lllllll}
\hline & $\Delta T\left({ }^{\circ} \mathrm{C}\right)$ & $\Delta t(\mathrm{~s})$ & $V_{\text {extruder }}\left(\mathrm{mm} \mathrm{s}^{-1}\right)$ & $V_{\text {reverse }}\left(\mathrm{mm} \mathrm{s}^{-1}\right)$ & $L(\mathrm{~mm})$ & $H(\mathrm{~mm})$ \\
\hline Case I & 70 & 1.625 & 12 & 40 & 15 & 55 \\
Case II & 120 & 4.333 & 12 & 40 & 40 & 55 \\
\hline
\end{tabular}

\section{Characterization methods}

\section{Differential scanning calorimetry (DSC)}

Differential scanning calorimetry (DSC) was accomplished using a TA instruments Q1000 (New Castle, USA). Four points located on the test parts have been selected to be characterized (see Fig. 6). Samples $(\sim 5.5 \mathrm{mg})$ were sealed in aluminum pans and heated from ambient temperature to $200{ }^{\circ} \mathrm{C}$ with heating rate of $10^{\circ} \mathrm{C} \mathrm{min}^{-1}$ to determine crystallization and melting temperatures of the filaments. Then, the crystallinity of PLA was calculated using the following equation [27]:

$X_{\mathrm{c}}=\left(\Delta H_{\mathrm{m}}-\Delta H_{\mathrm{c}}\right) / \Delta H_{\mathrm{m}}^{0}$

where $\Delta H_{\mathrm{c}}$ and $\Delta H_{\mathrm{m}}$ are cold crystallization and melting enthalpies, respectively, and the melting heat $\left(\Delta H_{\mathrm{m}}^{0}\right)$ of $100 \%$ crystalline PLA is considered equal to $93.7 \mathrm{j} \mathrm{g}^{-1}$ according to the literature [27].

\section{Quasi-static tensile test}

Tensile tests until failure have been performed on INSTRON 4301 machine. The specimen geometry used for quasi-static tensile tests is presented in "Test design and samples printing" section. However, based on the dimensional change that occurs during the process and specimen preparation, a digital caliper has been implemented to precisely measure the required dimension. All calculations regarding mechanical behavior have been proposed as mentioned. The loading velocity was $1 \mathrm{~mm} \mathrm{~min}^{-1}$.

\section{Microstructure characterization}

Microscopic observations, using scanning electronic microscope (HITACHI 4800 SEM), have been performed in order to qualitatively investigate the material microstructure and particularly bonding of adjacent filaments. ImageJ software was also utilized to evaluate the dimension variation using SEM micrographs.

\section{Online temperature measurement of filaments}

To track filaments cooling and the re-heating peaks of deposition of successive layers, a very small $(d=80 \mu \mathrm{m}) \quad$ K-type thermocouple was used (see $[28,29]$ for method description). 


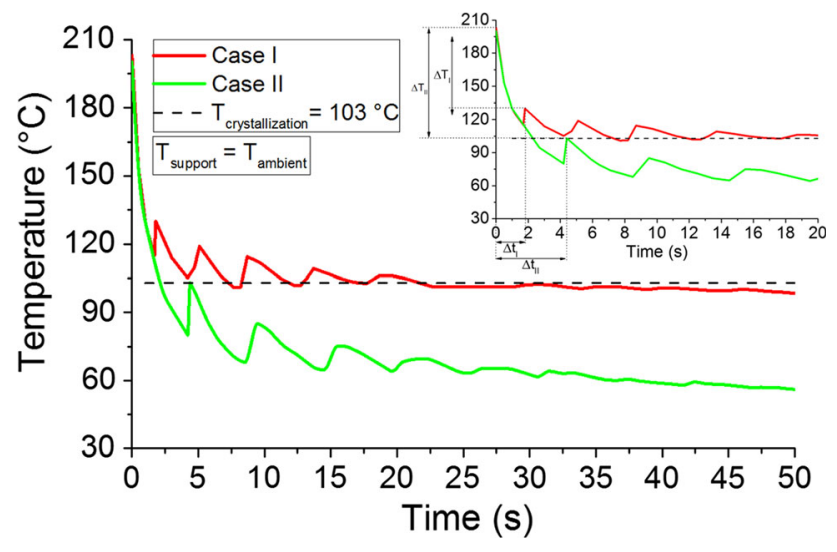

Figure 7 Results of the in situ measurement for the temperature evolution for both cases.

\section{Results and discussion}

\section{Temperature profile of the fabricated parts}

During test parts printing, temperature measurements were taken using in situ localized measurement device. The aim was to follow the temperature profile in a given location $L(X, H)$ (Fig. 7). The measured temperature profiles showed at their first part the cooling curve for the filament located in $L(X=5 \mathrm{~mm}, H=0.2 \mathrm{~mm}$ ) followed by several peaks corresponding to the successive filaments' depositions. Indeed, the filament located in $L(X=5 \mathrm{~mm}$, $H=0.2 \mathrm{~mm}$ ) undergoes a series of heating and cooling effects.

The red curve (Fig. 7), related to case I, shows that the depositions of filaments (2) (3) (4) and (5) bring the temperature of filament (1) higher than the crystallization temperature $T_{\mathrm{c}}$, while for the green curve, related to case II, only the deposition of filament (2) gets filament (1) temperature reaching $T_{\mathrm{c}}$. The depositions of the other filaments leave filament (1) temperature below $T_{\mathrm{c}}$. It is known that when the deposition of the current filament occurs at previously deposited filament temperatures greater or equal to the polymer crystallization temperature $T_{c}$, the degree of crystallinity across the interface will be higher, which will have great influence on the bonding strength development. Based on the latter, case I should present higher bonding strength (to be confirmed by tensile behavior tests).

\section{Characterization results}

\section{Material crystallinity}

DSC results for both test parts I and II are shown in Fig. 8. Using Eq. 6, the crystallinity in points 1, 2, 3 and 4 has been calculated, and the results are presented in Table 2. It appears from these results that crystallinity is higher in case I than in case II, thereby allowing to confirm the lower the cooling rate, the higher the possibility of crystallization.

The difference between point 1 and point 2 and between point 3 and point 4 could be explained by the series of heating and cooling effects generated during the deposition of the following filaments at point 1 and at point 3 , while at point 2 and 4 the heating and cooling effects are weak.

\section{Tensile behavior}

Moreover, tensile behaviors of both cases are illustrated in Fig. 9. Results indicate that the ultimate strength increases when the cooling rate decreases. It is worth mentioning that in the case of filaments deposition occurring at temperature greater or equal to $T_{\mathrm{c}}$, the degree of crystallinity is higher than in the 'high cooling rate case'. However, a detailed study is required in order to get precise information about material crystallinity and polymer re-arrangement.

Given the above-mentioned results and following the discussion performed on the mechanical behavior, tensile tests have been realized to illustrate the effect of the cooling rate ( $T_{\text {previous }}$ ) on the tensile behavior. The results presented in Fig. 9 and data collected in Table 3, are summarized as follows:

- Influence of $T_{\text {previous }}$ on Young's modulus is limited. When $T_{\text {previous }}$ is increased, young's modulus roughly changed from $0.5 \mathrm{GPa}$ in case I to $0.6 \mathrm{GPa}$ in case II.

- Average failure strain occurs around 3.9\%, and average failure stress occurs around $21 \mathrm{MPa}$.

- Finally, these results show $23 \%$ increase in the bonding strength for case I, confirming the influence and importance of the temperature of previously deposited filament, $T_{\text {previous }}$.

SEM micrographs for fractured samples (Fig. 10) show no local damage for case I as there might be a concentrated local damage at the failure zone. The 
Figure 8 DSC results of $\mathbf{a}$ case I and $\mathbf{b}$ case II.
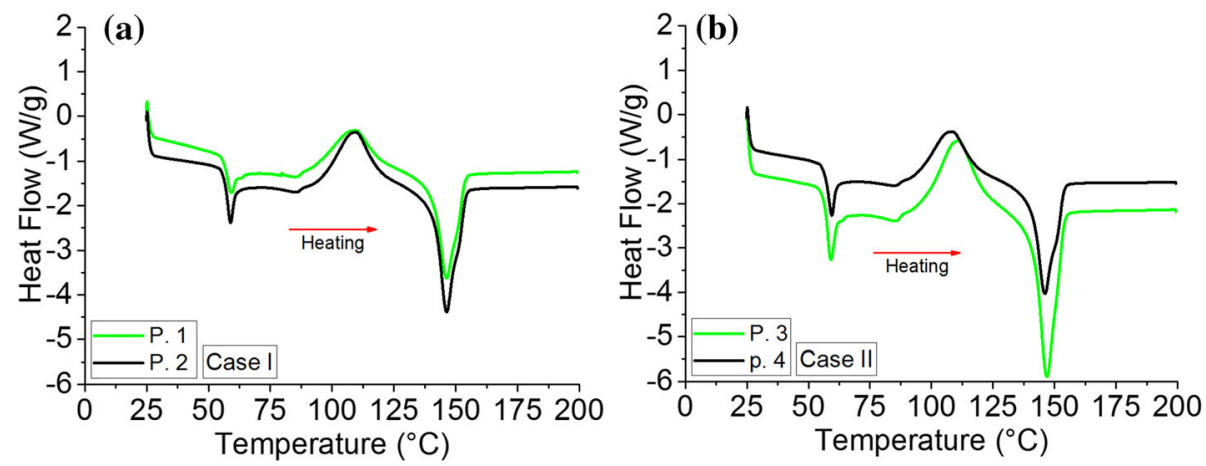

Table 2 Value of degree of crystallinity obtained from DSC

\begin{tabular}{ll}
\hline Conditions & \% Crystallinity \\
\hline Case I & \\
Point 1 & $8.3 \pm 0.2$ \\
Point 2 & $6.2 \pm 0.1$ \\
Case II & \\
Point 3 & $7.1 \pm 0.1$ \\
Point 4 & $6.0 \pm 0.2$ \\
\hline
\end{tabular}

sample failure happens suddenly, reflecting the higher mechanical strength in the inter-filament regions. However, SEM micrographs for case II show a series of local damage in the inter-filament region, which could explain its lower mechanical strength.

\section{Microstructure characterization}

Figure 11 presents the deposition sequence of filaments in both cases I and II. First observations show a significant difference between both cases, and an analysis on the SEM micrographs was performed for better understanding. In the context of this analysis, we carry out measures of the cross section of deposited filaments in both cases.

The results of the analysis performed on the cross section of deposited filaments for case I and II are presented in Fig. 12. The measurements show that when varying the previously deposited filament temperature ( $\left.T_{\text {previous }}\right)$, we observe $35 \%$ difference in filament deformation and slight structural subsidence
Figure 9 Representation of samples for tensile test for $\mathbf{a}$ case I and $\mathbf{b}$ case II with tensile behavior of $\mathrm{c}$ case I and d case II. (a)

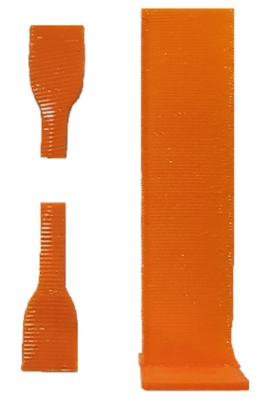

(c)

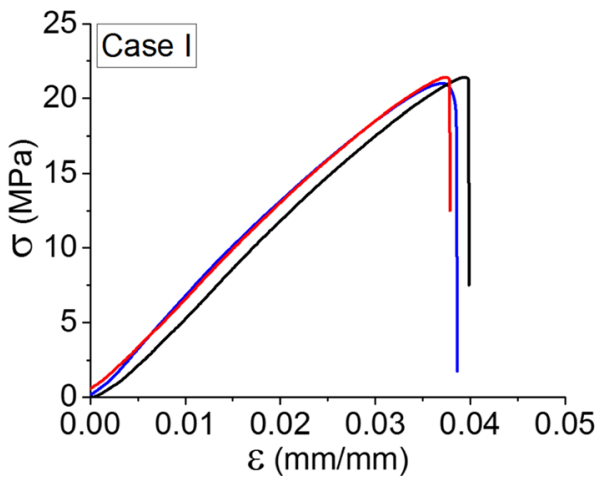

(b)
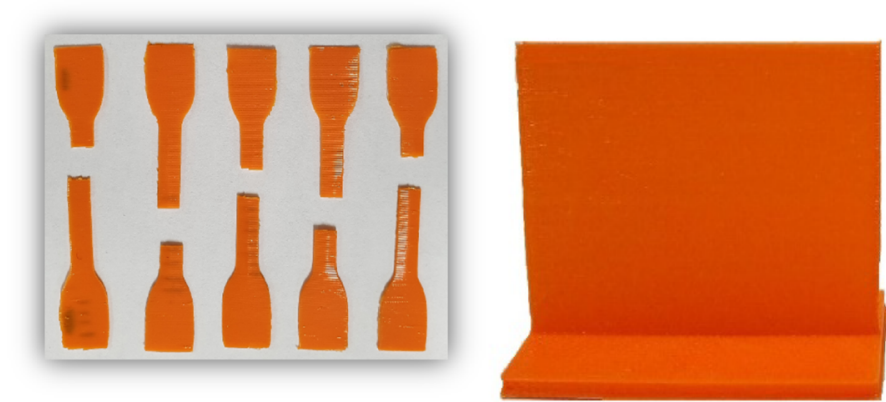

(d)

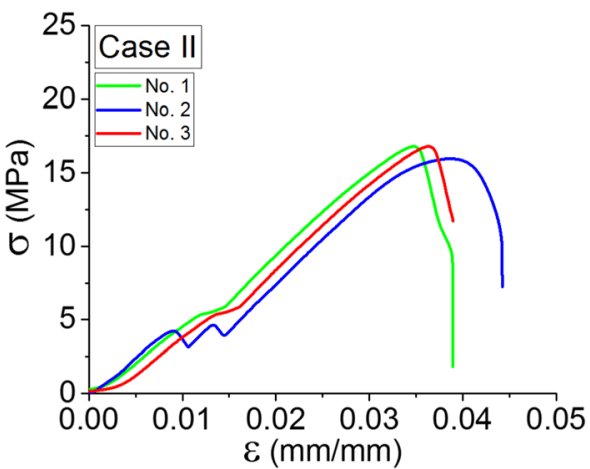


Table 3 Results of tensile behavior of printed PLA samples from cases I and II

\begin{tabular}{lllll}
\hline Samples & Location & $E(\mathrm{GPa})$ & $\sigma_{\max }(\mathrm{MPa})$ & $\varepsilon$ at $\sigma_{\max }(\%)$ \\
\hline Case I & N/a & $0.6 \pm 0.05$ & $21 \pm 2$ & $3.9 \pm 0.1$ \\
Case II & No. 1 & $0.51 \pm 0.01$ & $17 \pm 1.5$ & $3.5 \pm 0.2$ \\
& No. 2 & $0.5 \pm 0.01$ & $16 \pm 1.5$ & $3.9 \pm 0.3$ \\
& No. 3 & $0.5 \pm 0.01$ & $17 \pm 0.2$ & $3.6 \pm 0.2$ \\
\hline
\end{tabular}

of the wall (Fig. 12a-c). These results validate the effect of temperature evolution during fabrication on the geometry of both cases.

\section{Concluding remarks}

This work presents an experimental investigation on the effect of temperature difference $(\Delta \mathrm{T})$ between previous and current deposited layers temperatures on: (1) material crystallization and thus inter-layers bonding strength improvement and (2) dimensional and geometrical results of 3D-printed PLA. Two test cases were designed for having different temperatures of previously deposited filaments ( $T_{\text {previous }}$ ) which were proposed and studied. The main results are summarized as follows:

- The in situ measurements of filament temperature for case I indicate that the evolution of its filaments temperature remains above crystallization temperature $T_{\mathrm{c}}$, which allows better material crystallization.
Figure 10 SEM micrographs for $\mathbf{a}$ case I and $\mathbf{b}$ case II of the fractured sample. (a)
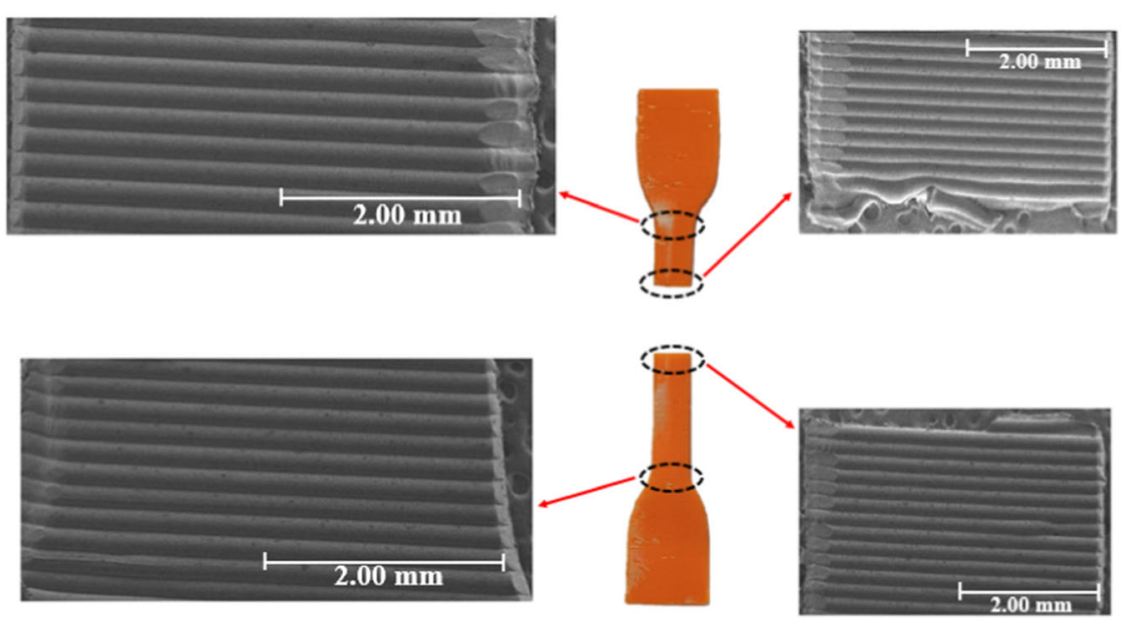

(b)

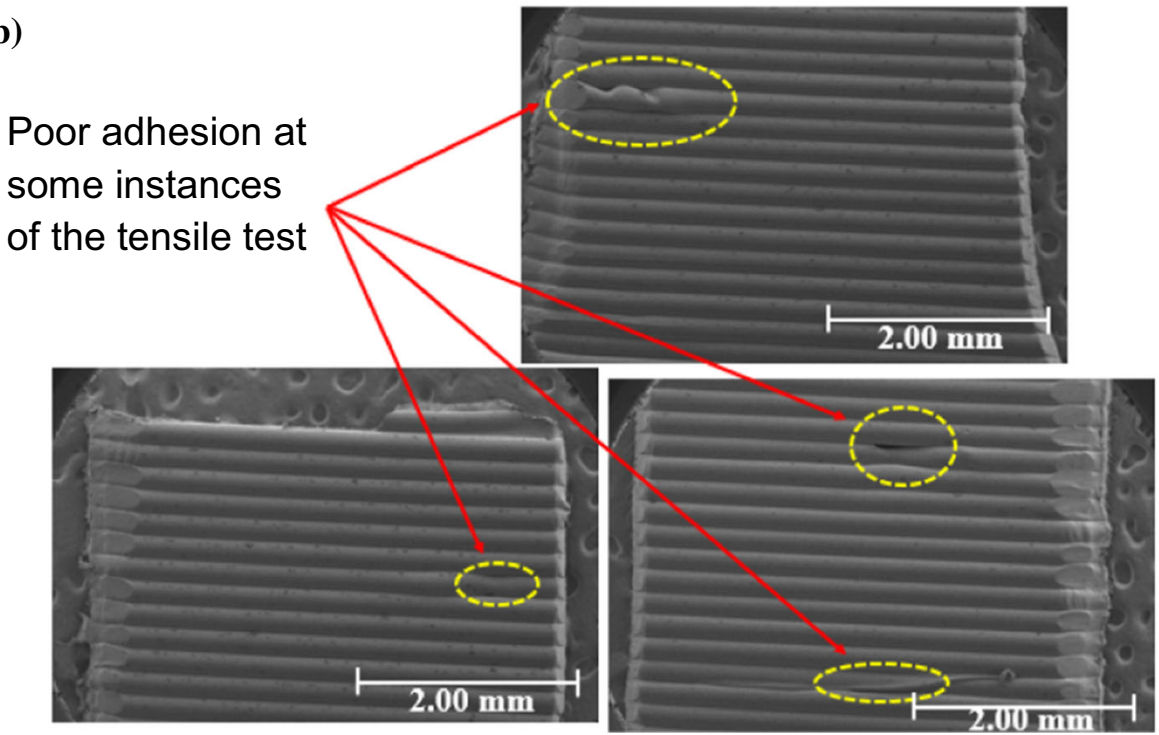


Figure 11 Consequence of deposited filaments in a case I for layers $1-11$, in case II for b layers 1-6, c layers 6-12 and $\mathbf{d}$ schematic representation of calculating the aspect ratio.
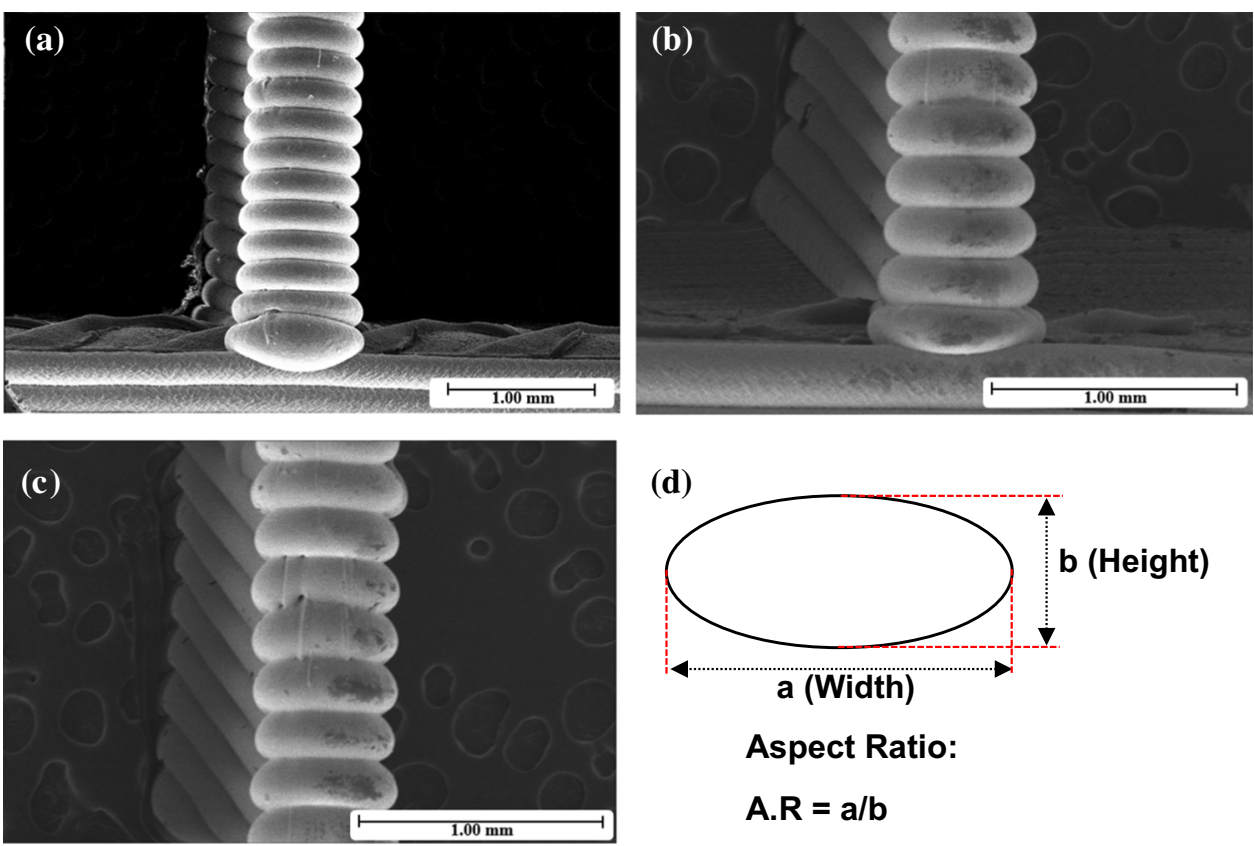

(d)

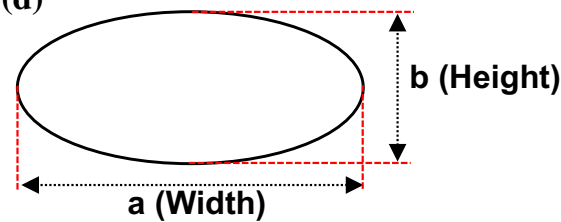

Aspect Ratio:

$A \cdot R=a / b$
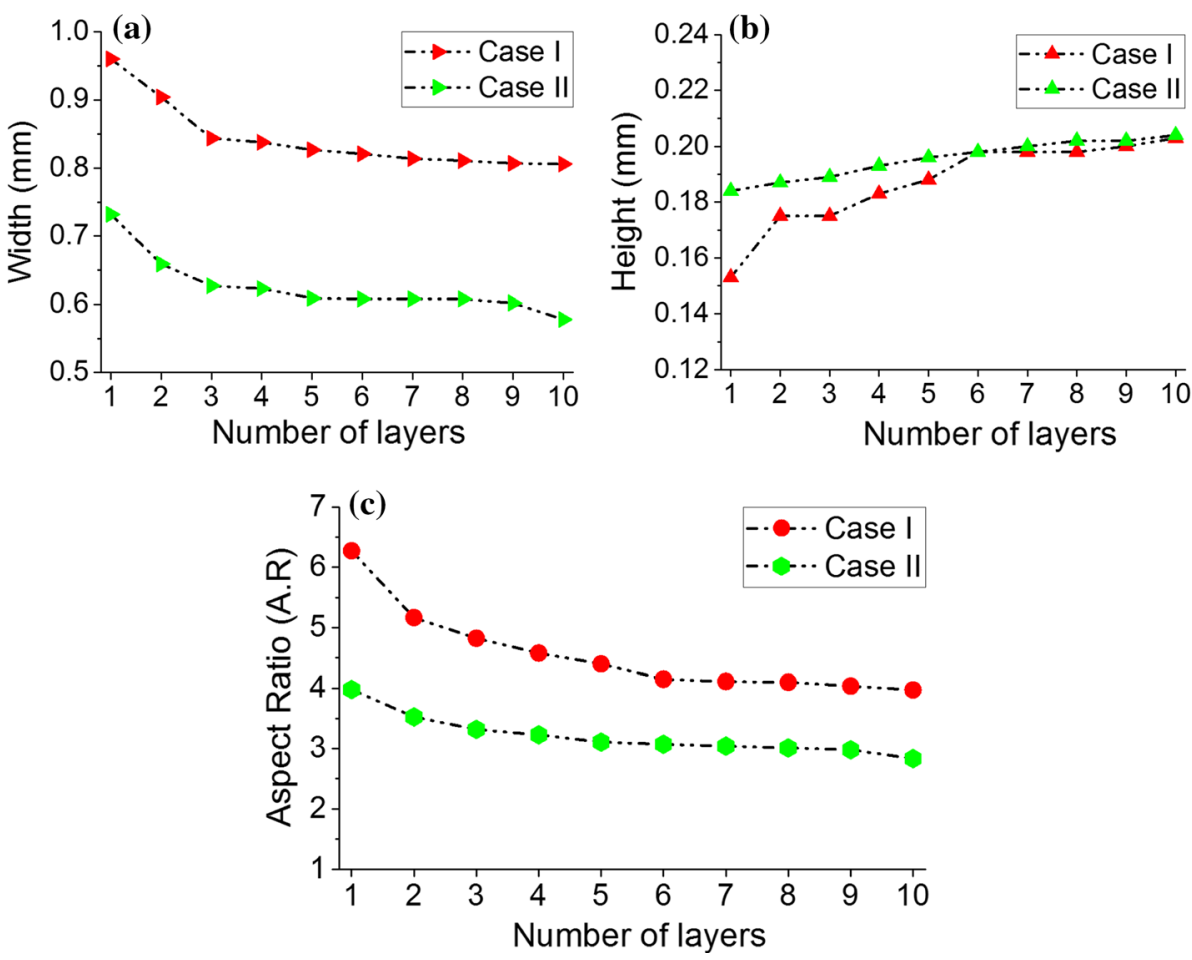

- The preliminary physicochemical and mechanical results showed higher values of crystallinity for case I ( $\left.T_{\text {previous }}=T_{\mathrm{c}}\right)$ leading to a better material crystallinity.

- Tensile experiments showed that there is almost 23\% increase in the inter-layer bond strength for case I.
- Measurements of the cross-section variation of the deposited filaments show almost 35\% difference between both cases, showing the effect of temperature evolution on the geometry of both cases.

The results of our experiments confirm that when the deposition of the current filament (1) occurs at 
previously deposited filament (2) temperatures greater or equal to the polymer crystallization temperature $T_{\mathrm{c}}$ (case I), the inter-filaments bonding strength will be higher. Likewise, when the depositions of filaments (3), (4), (5)... bring the temperature of filament (1) to a temperature greater or equal to the crystallization temperature $T_{c}$, the inter-filaments bonding strength will undergo an additional improvement.

This research is a preliminary study into understanding and improving temperature aspects and inter-layers bonding. In future developments, we will focus our attention on defining a solution about local pre-heating helping to control previously deposited layer temperature close to crystallization temperature during the printing. When implemented on 3D printers, this solution should ensure higher mechanical strength of printed parts.

\section{Compliance with ethical standards}

Conflict of interest The authors certify that they have NO affiliations with or involvement in any organization or entity with any financial interest, or non-financial interest in the subject matter or materials discussed in this manuscript.

\section{References}

[1] Mohamed OA, Masood SH, Bhowmik JL (2015) Optimization of fused deposition modeling process parameters: a review of current research and future prospects. Adv Manuf 3(1):42-53. https://doi.org/10.1007/s40436-014-0097-7

[2] Holmström J, Partanen J, Tuomi J, Walter M (2010) Rapid manufacturing in the spare parts supply chain: alternative approaches to capacity deployment. J Manuf Technol Manag 21(6):687-697. https://doi.org/10.1108/17410381011063996

[3] Iftikhar A et al (2013) Turbine blade manufacturing through rapid tooling (RT) process and its quality inspection. Mater Manuf Process 28(5):534-538. https://doi.org/10.1080/1042 6914.2012 .746698

[4] Yagnik D (2014) Fused deposition modeling - a rapid prototyping technique for product cycle time reduction cost effectively in aerospace applications. IOSR J Mech Civ Eng 5:62-68

[5] Chennakesava P, Narayan YS (2014) Fused deposition modeling-insights. In: Proceedings of the international conference on advances in design and manufacturing ICAD\&M, vol 14, pp 1345-1350
[6] Turner BN, Strong R, Gold SA (2014) A review of melt extrusion additive manufacturing processes: I. Process design and modeling. Rapid Prototyp J 20(3):192-204. h ttps://doi.org/10.1108/RPJ-01-2013-0012

[7] Abbott A, Tandon G, Bradford R, Koerner H, Baur J (2018) Process-structure-property effects on ABS bond strength in fused filament fabrication. Addit Manuf 19:29-38. https://d oi.org/10.1016/S1526-6125(04)70071-7

[8] Bellehumeur C, Li L, Sun Q, Gu P (2004) Modeling of bond formation between polymer filaments in the fused deposition modeling process. J Manuf Process 6(2):170-178. https://d oi.org/10.1016/S1526-6125(04)70071-7

[9] Oladapo BI, Obisesan OB, Oluwole B, Adebiyi VA, Usman H, Khan A (2020) Mechanical characterization of a polymeric scaffold for bone implant. J Mater Sci. https://doi.org/ 10.1007/s10853-020-04638-y

[10] Vanaei H et al (2020) Influence of process parameters on thermal and mechanical properties of polylactic acid fabricated by fused filament fabrication. Polym Eng Sci. https://d oi.org/10.1002/pen.25419

[11] Sweeney M, Campbell LL, Hanson J, Pantoya ML, Christopher GF (2017) Characterizing the feasibility of processing wet granular materials to improve rheology for 3D printing. J Mater Sci 52(22):13040-13053. https://doi. org/10.1007/s10853-017-1404-z

[12] Naghieh S, Ravari MK, Badrossamay M, Foroozmehr E, Kadkhodaei M (2016) Numerical investigation of the mechanical properties of the additive manufactured bone scaffolds fabricated by FDM: the effect of layer penetration and post-heating. J Mech Behav Biomed Mater 59:241-250. https://doi.org/10.1016/j.jmbbm.2016.01.031

[13] Widden M, Gunn K (2010) Design-build-test of model aerofoils for engineering education using FDM. Virtual Phys Prototyp 5(4):189-194. https://doi.org/10.1080/17452759.2 010.528841

[14] Pandey PM, Venkata Reddy N, Dhande SG (2006) Virtual hybrid-FDM system to enhance surface finish. Virtual Phys Prototyp 1(2):101-116. https://doi.org/10.1080/ 17452750600763905

[15] Sun Q, Rizvi G, Bellehumeur C, Gu P (2008) Effect of processing conditions on the bonding quality of FDM polymer filaments. Rapid Prototyp J 14(2):72-80. https://doi. org/10.1108/13552540810862028

[16] Costa S, Duarte F, Covas J (2017) Estimation of filament temperature and adhesion development in fused deposition techniques. J Mater Process Technol 245:167-179. https://d oi.org/10.1016/j.jmatprotec.2017.02.026

[17] Zhou X, Hsieh S-J, Sun Y (2017) Experimental and numerical investigation of the thermal behaviour of polylactic acid during the fused deposition process. Virtual Phys 
Prototyp 12(3):221-233. https://doi.org/10.1080/17452759. 2017.1317214

[18] Polychronopoulos ND, Vlachopoulos J (2020) The role of heating and cooling in viscous sintering of pairs of spheres and pairs of cylinders. Rapid Prototyp J. https://doi.org/10. 1108/RPJ-06-2019-0162

[19] Kamyabi M, Sotudeh-Gharebagh R, Zarghami R, Saleh K (2019) Analysis of non-isothermal viscous flow coalescence at micro scale. Can J Chem Eng 97(9):2565-2572. https://d oi.org/10.1002/cjce.23499

[20] Yin J, Lu C, Fu J, Huang Y, Zheng Y (2018) Interfacial bonding during multi-material fused deposition modeling (FDM) process due to inter-molecular diffusion. Mater Des 150:104-112. https://doi.org/10.1016/j.matdes.2018.04.029

[21] Levenhagen NP, Dadmun MD (2017) Bimodal molecular weight samples improve the isotropy of $3 \mathrm{D}$ printed polymeric samples. Polymer 122:232-241. https://doi.org/10.10 16/j.polymer.2017.06.057

[22] Levenhagen NP, Dadmun MD (2018) Interlayer diffusion of surface segregating additives to improve the isotropy of fused deposition modeling products. Polymer 152:35-41. h ttps://doi.org/10.1016/j.polymer.2018.01.031

[23] de León A, Domínguez-Calvo A, Molina S (2019) Materials with enhanced adhesive properties based on acrylonitrilebutadiene-styrene (ABS)/thermoplastic polyurethane (TPU) blends for fused filament fabrication (FFF). Mater Des 182:108044. https://doi.org/10.1016/j.matdes.2019.108044
[24] Partain SC (2007) Fused deposition modeling with localized pre-deposition heating using forced air, Montana State University-Bozeman, College of Engineering

[25] Kishore $\mathrm{V}$ et al (2017) Infrared preheating to improve interlayer strength of big area additive manufacturing (BAAM) components. Addit Manuf 14:7-12. https://doi.org/ 10.1016/j.addma.2016.11.008

[26] Ravi AK, Deshpande A, Hsu KH (2016) An in-process laser localized pre-deposition heating approach to inter-layer bond strengthening in extrusion based polymer additive manufacturing. J Manuf Process 24:179-185. https://doi.org/10. 1016/j.jmapro.2016.08.007

[27] Vadori R, Mohanty AK, Misra M (2013) The effect of mold temperature on the performance of injection molded poly (lactic acid)-based bioplastic. Macromol Mater Eng 298(9):981-990. https://doi.org/10.1002/mame.201200274

[28] Vanaei HR et al (2020) Experimental study of PLA thermal behavior during fused filament fabrication (FFF). J Appl Polym Sci. https://doi.org/10.1002/app.49747

[29] Lucas A et al (2019) Conventional rotational molding process and aerodynamic characteristics of an axial-flow hollow blades rotor. Int J Adv Manuf Technol 104(1-4):1183-1194. https://doi.org/10.1007/s00170-019-03962-1 